\title{
Teorías de conspiración y desinformación en torno a la epidemia de la COVID-19.
}

\author{
Conspiracy theories and misinformation related to the COVID-19 epidemic.
}

\section{Johann M. Vega-Dienstmaier 1,a,b}

Durante la presente pandemia, se ha difundido una gran cantidad de información falsa o inexacta respecto a la propia existencia de la COVID-19, su origen, relevancia, las formas de contagio, las medidas de prevención y el tratamiento.

La epidemia ha sido una situación propicia para la aparición de diversas teorías de conspiración. Una de ellas sostiene que la COVID-19 en realidad no existe o que no es más que una simple gripe y que las tasas de mortalidad por COVID-19 están siendo infladas intencionalmente, entre otras formas, manipulando los certificados de defunción. El engaño sería producto de un complot de las personas más poderosas del mundo para quitarle la libertad a la población. Estas creencias difundidas activamente en redes sociales han generado protestas en contra de las medidas preventivas tales como el distanciamiento social, el uso de mascarillas y la cuarentena en varios lugares de Estados Unidos (1).

Otra teoría involucra a Bill Gates, el multimillonario cofundador de Microsoft, a quien se le acusa de haber creado el virus para tener la oportunidad de administrar masivamente una supuesta vacuna y junto con ella un microchip o un mecanismo de nanotecnología que serviría para monitorear y controlar a la población (2). La teoría se basaría en el hecho de que Gates financia investigaciones para desarrollar tratamientos, vacunas y tecnología para controlar la pandemia y además en el año 2015 advirtió en un video TED que el mundo estaba en riesgo de una epidemia global y que no estaba preparado para afrontarla (3).

Por otra parte, se ha difundido la creencia de que la tecnología de celulares 5G genera la diseminación de la infección por el SARS-CoV-2, lo cual ha llevado a grupos de fanáticos a destruir antenas de telecomunicaciones en varios países (4). En Huancavelica (Perú), se ha llegado a secuestrar a trabajadores que estaban haciendo mantenimiento a las antenas de telefonía móvil (5).

Finalmente otras teorías conspirativas sostienen que el virus se ha escapado del laboratorio de virología de Wuhan (donde comenzó la pandemia); que es un arma biológica creada por China en contra de Estados Unidos y sus aliados; y al contrario, que ha sido generado por Estados Unidos en contra de China; asimismo, se ha responsabilizado a los alimentos transgénicos y a las grandes empresas farmacéuticas (1).

Brotherton (6), en su libro Suspicious Minds, comenta que las teorías de conspiración son el resultado de la necesidad de encontrar explicaciones a preguntas sin respuesta y describe una serie de ellas que han ocurrido a lo largo de la historia, por ejemplo: 1) Que el incendio de Roma del año 64 antes de Cristo fue planeado por Nerón; 2) Que los judíos eran culpables de la mortal epidemia de peste bubónica de la Edad Media, lo cual condujo a su persecución y asesinato; 3) Que desde el siglo XVIII la sociedad secreta de los "Illuminati” controla varios eventos en el mundo: propició la Revolución Francesa, planificó el asesinato de John F. Kennedy y ejerce actualmente poder sobre el gobierno de los Estados Unidos; 4) Que en el siglo XIX, los Sabios de Sion, un grupo de líderes judíos,

Facultad de Medicina Alberto Hurtado, Universidad Peruana Cayetano Heredia, ${ }^{a}$ Médico-psiquiatra, Profesor asociado.

b ORCID: 0000-0002-5686-4014 
Vega-Dienstmaier J.

estaban conspirando para generar guerras y controlar el mundo; posteriormente se les culpó de la Primera Guerra Mundial y de la Gran Depresión; lo cual sirvió de base a Hitler para justificar el exterminio judío; 5) Que el atentado del 11 de septiembre fue planeado por el gobierno de Estados Unidos para justificar una guerra en el Medio Oriente; y 6) Que el calentamiento global es una farsa elaborada por los científicos y ciertos políticos para manipular a la población.

Un grupo denominado "Médicos por la Verdad" sostiene que la COVID-19 es una mentira creada por "oscuros poderes" con la finalidad de quebrar las economías de los países e instalar regímenes comunistas; y los casos que se reportan corresponderían simplemente a una "típica gripe invernal" (7); sus integrantes están en contra de la cuarentena, del uso de mascarillas en la población general (argumentando que tienen efectos dañinos) y de la posibilidad de emplear una vacuna cuando esté disponible, proponiendo que se permita que aparezca la inmunidad colectiva. Por otro lado, aunque niegan la enfermedad, sostienen que puede tratarse o prevenirse con ozono, dióxido de cloro y peróxido de hidrógeno.

Creer en una teoría se asocia a creer en otras aunque sean contradictorias, lo cual sugiere que algunas personas tienen una tendencia a creer en conspiraciones (6).

Podría pensarse que estas teorías de conspiración las presentan principalmente individuos con tendencia a la psicosis, pero son más comunes de lo que se esperaría. Un estudio realizado en línea en la población de Estados Unidos encontró que la creencia en las teorías de conspiración relacionadas a la pandemia de la COVID-19 es frecuente variando entre $8 \%$ y $52 \%$; por ejemplo, $46 \%$ pensaba que Bill Gates estaría creando un dispositivo de rastreo que sería inyectado junto con la vacuna para el coronavirus, $22 \%$ creía que la tecnología $5 \mathrm{G}$ causaba una diseminación más rápida del virus y $8 \%$ creía que la epidemia era una farsa (8). Estas creencias se ven estimuladas también por personajes importantes como políticos y artistas quienes las sostienen y difunden $(9,10)$.

Existen tratamientos sin eficacia demostrada para la COVID-19 que se promueven a través de redes sociales e Internet, entre ellos tenemos las dietas alcalinas, bebidas calientes, inhalaciones de vapor de agua, ungüentos con mentol y eucalipto, gárgaras con antisépticos, bebidas alcohólicas, warfarina, naproxeno, aspirina y dióxido de cloro (11). Este último, es muy polémico e involucra a las teorías de conspiración, sosteniéndose que hay una campaña de la industria farmacéutica para desprestigiar su utilización con el fin de evitar que caigan las ventas de sus medicamentos debido a la alta eficacia del dióxido de cloro. Sus defensores sostienen que el dióxido de cloro combate la infección por coronavirus basándose en su eficacia como desinfectante y su uso en la potabilización del agua. Se hace una extrapolación de su actividad microbicida fuera del cuerpo a su efecto dentro del mismo; sin embargo, no existe evidencia científica que respalde su eficacia para la COVID-19 (12). Si bien es cierto, se han difundido en medios no científicos casos de pacientes que han sido tratados con dióxido de cloro y han mejorado, estos reportes anecdóticos no se pueden tomar como evidencia de eficacia considerando que el pronóstico es favorable en la mayor parte de pacientes con la COVID-19 y una mejoría bien puede explicarse por curso natural de la enfermedad.

Asimismo, se han reportado casos de efectos adversos debidos a automedicación con warfarina cuyo uso ha sido promovido por profesionales de la salud a través de los medios de comunicación (13).

Para entender cómo las personas llegan a tener estas creencias y a autoengañarse, debemos considerar que la mente tiene una necesidad de coherencia entre sus ideas: si una idea nueva encaja adecuadamente con las previas, ésta tiende a ser aceptada; pero si no, es probable que sea rechazada. De este modo se evita la disonancia cognitiva (14), se prefiere la coherencia a costa de la verdad.

Otro aspecto a tener en cuenta es que las emociones influyen sobre la aceptación o rechazo de las creencias, como ocurre con las ideas sobrevaloradas (15). Si se desea que algo sea cierto, es más fácil creer en ello, como por ejemplo, que la COVID-19 no es real o que existen tratamientos milagrosos que la curan o previenen.

La creencia en las teorías de conspiración puede originarse o propiciarse por varios factores, entre ellos: la necesidad de tener una explicación ante situaciones que generan incertidumbre (8); la presencia de rasgos 
Teorías de conspiración y desinformación en torno a la epidemia de la COVID-19.

esquizotípicos caracterizados por un pensamiento mágico y creencias inusuales (16); un pensamiento de tipo conspirativo (8), caracterizado por la tendencia a creer cosas como, por ejemplo, que la mayor parte de la vida de las personas es controlada por planes tramados en lugares secretos o que quienes dirigen los países no son los líderes políticos sino gente poderosa que los controla secretamente y que pretende someter al mundo (17); actitudes psicopáticas, manipuladoras, dominantes y crueles (16); la predisposición a rechazar la información proporcionada por expertos (negacionismo) (17); e intereses de partidos políticos (17).

Promover y desarrollar el pensamiento científico, la objetividad y las creencias basadas en evidencias es muy importante para evitar la desinformación, la proliferación de las teorías de conspiración y los riesgos que implican, tales como, la dificultad para instalar medidas de prevención contra la diseminación del virus, el uso de tratamientos ineficaces o peligrosos y la generación de más ansiedad de la ya existente por la propia pandemia.

\section{REFERENCIAS BIBLIOGRÁFICAS}

1. Lynas M. COVID: 10 principales teorías de conspiración. New York: Alliance for Science; 2020. (Citado el 20 de Julio del 2020) Disponible en: https:// allianceforscience.cornell.edu/blog/2020/05/covid10-principales-teorias-de-conspiracion/

2. Ball P, Maxmen A. The epic battle against coronavirus misinformation and conspiracy theories. Nature. 2020;581: 371-374.

3. TED. Bill Gates: ¿La próxima epidemia? No estamos listos. Youtube; 3 Abril 2015. (Citado el 20 de agosto del 2020) Disponible en: https://www.youtube.com/ watch?v=6Af6b_wyiwI

4. Eliassen I, Pena P. Real 5G issues overshadowed by Covid-19 conspiracy theories. New York: The 5G Mass Experiment; 12 Junio 2020. (Citado el 28 de Julio del 2020) Disponible en: https://www. investigate-europe.eu/en/2020/5g-covid-conspiracy/

5. De La Quintana J. Liberan en Perú a trabajadores secuestrados por hacer mantenimiento a antenas que, según la población, propagan el covid-19; Atlanta: CNN; 16 Jun 2020. (Citado el 28 de Julio del 2020) Disponible en: https://cnnespanol.cnn.com/2020/ 06/16/alerta-peru-liberan-a-trabajadoressecuestrados-por-hacer-mantenimiento-a-antenasque-segun-la-poblacion-propagan-el-covid-19/

6. Brotherton R. Suspicious Minds: Why We Believe Conspiracy Theories. Londres: Bloomsbury Sigma; 2015.

7. Noticias Ocultas X. ¡Difundir! Médicos del Mundo Unidos por la Verdad. Youtube; 26 jul 2020 (Citado el 4 de setiembre del 2020) Disponible en: https:// www.youtube.com/watch?v=xI4bmxQflzc

8. Miller JM. Psychological, political, and situational factors combine to boost COVID-19 conspiracy theory beliefs. Canadian Journal of Political Science. 2020; 53: 327-334. doi:10.1017/S000842392000058X

9. 20minutos. Más allá de Miguel Bosé: los famosos que hablan de teorías conspirativas sobre la pandemia del coronavirus.Madrid: 20minutos; 11 de agosto de 2020. (Citado el 4 de setiembre del 2020) Disponible en: https://www.20minutos.es/noticia/4349621/0/ de-miguel-bose-a-enrique-bunbury-los-famososque-hablan-de-teorias-conspirativas-sobre-elcoronavirus/

10. Paredes LM. Artistas y famosos que no creen en el Covid-19 ni en las mascarillas (y que contribuyen con la desinformación). Yahoo Noticias;18 Aug 2020. (Citado el 4 de setiembre del 2020) Disponible en: https://es.noticias.yahoo.com/artistas-famososcreen-covid-19-221544622.html

11. Facultad de Medicina Alberto Hurtado, Universidad Peruana Cayetano Heredia. La Vacuna Digital. Lima: Facultad de Medicina Alberto Hurtado, Universidad Peruana Cayetano Heredia; 2020. (Citado el 28 de Julio del 2020) Disponible en: https://lavacunadigital. $\mathrm{com} /$

12. Instituto Nacional de Salud; Unidad de Análisis y Generación de Evidencias en Salud Pública. Eficacia y seguridad del dióxido de cloro para el tratamiento de COVID-19.; Report No.: 24-2020Lima: Instituto Nacional de Salud;2020. (Citado el 28 de Julio del 2020) Disponible en: https://web.ins.gob.pe/sites/ default/files/Archivos/authenticated $\% 2 \mathrm{C} \% 20$ administrator $\% 2 \mathrm{C} \% 20$ editor/publicaciones/ 2020-08-04/SE_24_dioxido\%20de\%20cloro.pdf

13. Federación Médica Peruana. Comunicado N ${ }^{\circ} 56$ : Prevención de daños en la salud por automedicación del medicamento Warfarina. Lima: Federación Médica Peruana; 2020. Publicaciones. (Citado el 14 de setiembre del 2020) Disponible en: https:// www.facebook.com/FMedicaPeruana/posts/ 2949038571859508/

14. Boring EG. Cognitive dissonance: Its use in science. Science. 1964;145: 680-685.

15. Veale D. Over-valued ideas: a conceptual analysis. Behav Res Ther. 2002;40: 383-400.

16. March E, Springer J. Belief in conspiracy theories: The predictive role of schizotypy, Machiavellianism, and primary psychopathy. PLoS One. 2019;14: e0225964.

17. Uscinski JE, Enders AM, Klofstad C, Seelig M, Funchion J, Everett C, et al. Why do people believe COVID-19 conspiracy theories? HKS Misinfo Review. 2020. doi:10.37016/mr-2020-015 